\title{
Recommendations for the Use of Testosterone in Male Transgender*
}

\section{Recomendações para o uso da testosterona em homens transgêneros*}

\author{
Laura Bregieiro Fernandes Costa ${ }^{1}$ Ana Carolina Japur de Sá Rosa-e-Silva ${ }^{2}$ Sebastião Freitas de Medeiros ${ }^{3}$ \\ Andrea Prestes Nacul ${ }^{4}$ Bruno Ramalho de Carvalho ${ }^{5}$ Cristina Laguna Benetti-Pinto ${ }^{6}$ \\ Daniela Angerame Yela ${ }^{6}$ Gustavo Arantes Rosa Maciel ${ }^{7}$ José Maria Soares Júnior ${ }^{7}$ \\ Técia Maria de Oliveira Maranhão ${ }^{8}$
}

${ }^{1}$ Discipline of Gynecology and Obstetrics, Universidade de Pernambuco, Recife, PE, Brazil

${ }^{2}$ Department of Gynecology and Obstetrics, Faculdade de Medicina de Ribeirão Preto, Universidade de São Paulo, Ribeirão Preto, SP, Brazil

${ }^{3}$ Department of Gynecology and Obstetrics, Faculdade de Medicina, Universidade Federal do Mato Grosso, Cuiabá, MT Brazil

${ }^{4}$ Hospital Fêmina, Grupo Hospitalar Conceição, Porto Alegre, RS, Brazil

${ }^{5}$ Bonvena Reproduticve Medicine, Brasília, DF, Brazil

${ }^{6}$ Department of Gynecology and Obstetrics, Faculdade de Ciências Médicas, Universidade Estadual de Campinas, Campinas, SP, Brazil

${ }^{7}$ Discipline of Gynecology, Faculdade de Medicina de São Paulo,

Universidade de São Paulo, São Paulo, SP, Brazil

8 Department of Obstetrics and Gynecology, Faculdade de Medicina, Universidade Federal do Rio Grande do Norte, Natal, RN, Brazil
Address for correspondence Cristina Laguna Benetti-Pinto, Faculdade de Ciências Médicas, Universidade Estadual de Campinas, Av. Alexander Fleming, 101, 13083-881, Cidade Universitária, Campinas, SP, Brazil (e-mail: laguna.unicamp@gmail.com).

* This revision was elaborated by the Specialized National Committees on Endocrine Gynecology at Federação Brasileira das Associações de Ginecologia e Obstetrícia. All authors are members of the Commission.

Rev Bras Ginecol Obstet 2018;40:275-280.

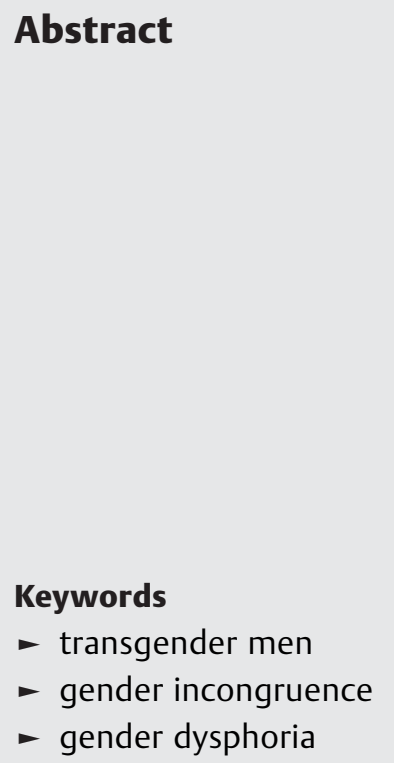

Gender incongruence is defined as a condition in which an individual self-identifies and desires to have physical characteristics and social roles that connote the opposite biological sex. Gender dysphoria is when an individual displays the anxiety and/or depression disorders that result from the incongruity between the gender identity and the biological sex. The gender affirmation process must be performed by a multidisciplinary team. The main goal of the hormone treatment is to start the development of male physical characteristics by means of testosterone administration that may be offered to transgender men who are 18 years old or over. The use of testosterone is usually well tolerated and improves the quality of life. However, there is still lack of evidence regarding the effects and risks of the long-term use of this hormone. Many different pharmacological formulations have been used in the transsexualization process. The most commonly used formulation is the intramuscular testosterone esters in a short-term release injection, followed by testosterone cypionate or testosterone enanthate. In the majority of testosterone therapy protocols, the male physical characteristics can be seen in almost all users after 6 months of therapy, and the maximum virilization effects are usually achieved after 3 to 5 years of regular use of received

March 1, 2018

accepted

April 16, 2018
DOI https://doi.org/

10.1055/s-0038-1657788. ISSN 0100-7203.
Copyright $\odot 2018$ by Thieme Revinter Publicações Ltda, Rio de Janeiro, Brazil
License terms

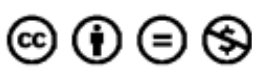




\section{Resumo}

\section{Palavras-chave}

- homens transgênero

- incongruência de gênero

- disforia de gênero the hormone. To minimize risks, plasmatic testosterone levels should be kept within male physiological ranges (300 to $1,000 \mathrm{ng} / \mathrm{dl}$ ) during hormonal treatment. It is recommended that transgender men under androgen therapy be monitored every 3 months during the 1 st year of treatment and then, every 6 to 12 months.

Incongruência de gênero é uma condição na qual o indivíduo se identifica, deseja viver e ser aceito como uma pessoa do gênero oposto ao designado por ocasião do nascimento. Na disforia de gênero o indivíduo manifesta ansiedade e sofrimento pelo desejo de viver e ser aceito como uma pessoa do gênero oposto ao designado ao nascimento. O processo transsexualizador requer trabalho em equipe multiprofissional. $\mathrm{O}$ objetivo do tratamento hormonal é induzir o aparecimento de características sexuais masculinas secundárias por meio da administração da testosterona em indivíduos com idade igual ou superior a 18 anos. O tratamento de estimulação androgênica costuma ser bem tolerado. Entretanto, ainda não existem evidências sobre os efeitos e riscos do uso da testosterona a longo prazo. Diferentes preparações farmacológicas da testosterona têm sido utilizadas. As mais utilizadas têm sido as injeções intramusculares de administração a curto prazo de ésteres, seguidas do cipionato de testosterona e do enantato de testosterona. Na maioria dos protocolos de tratamento observa-se o aparecimento de características corporais masculinas nos primeiros 6 meses, e a obtenção do máximo efeito da estimulação androgênica, após 3 a 5 anos de uso regular da testosterona. Recomenda-se a manutenção dos níveis plasmáticos de testosterona dentro dos limites fisiológicos para o sexo masculino (300 a $1.000 \mathrm{ng} / \mathrm{dl}$ ), a fim de minimizar os riscos. A monitorização dos homens transgênero é recomendada a cada 3 meses durante o primeiro ano de tratamento e a seguir, a cada 6 a 12 meses.

\section{Introduction}

According to the 10th revision of the International Statistical Classification of Diseases and Related Health Problems (ICD-10), transsexualism (F64.0) is defined as a condition in which an individual self-identifies and desires to have physical characteristics and social roles that connote the opposite biological sex. ${ }^{1}$ Gender incongruence is the proposed name of the gender identity-related diagnoses in the 11 th revision of the ICD (ICD-11). Not all individuals with gender incongruence have gender dysphoria or seek treatment. According to the $4^{\text {th }}$ Edition of the Diagnostic and Statistical Manual of Mental Disorders(DSM-4) from the American Society of Psychiatry, in the gender identity disorder, the individual manifests marked anxiety, discomfort and suffering, because of the desire to live and be accepted as someone with the opposite gender than the one designated at birth, independently of the sexual orientation. Recently, on the $5^{\text {th }}$ Edition of the DSM (DSM-5), the term "gender identity disorder" was substituted for "gender dysphoria" (GD)., ${ }^{2,3}$

Usually, these individuals manifest a strong desire to define a social identity and redesign their physical appearance according to the gender of identification by means of hormonal therapy and/or surgical procedures.

The recognition and acceptance of transgender women (individuals $46 \mathrm{XY}$, with male phenotype and female identity) and transgender men (individuals $46 \mathrm{XX}$, with female phenotype and male identity) have increased in the last decade, both among health providers and among the general population. $^{2}$

In the Brazilian Public Health System (SUS, in the Portuguese acronym), the transsexualization process was institutionalized by means of the ministerial order SAS/MS-457, stated on August $19^{\text {th }}, 2008$. This determination established guidelines to regulate clinical and surgical procedures that could be used to adapt the genital status to match gender identification in transgender individuals. In 2010, the Brazilian Federal Council of Medicine (CFM, in the Portuguese acronym), by means of the $1995 / 2010$ resolution, authorized and amplified the surgical procedures for sexual reassignment, since these procedures were officially approved by the Ministry of Health (MS, in the Portuguese acronym). After that, on November $19^{\text {th }}, 2013$, a new determination published by the MS, GM/MS 2,803, ${ }^{4}$ redefined and amplified the management of the transsexualization process in the SUS, which now, besides including new procedures, also allowed a larger number of health centers to be enabled to offer treatment to this population. Nowadays, centers registered to offer medical assistance to transgender individuals must be capable of offering integral care, from the primary care to the specific and specialized assistance, in a multidisciplinary and interdisciplinary effort. According to the World Professional Association for Transgender Health (WPATH) ${ }^{5}$ and the MS in Brazil (regulatory ordinance $n^{\circ}$ 2.803, 2013 
November $19^{\text {th }}$ Art. 13), ${ }^{4}$ it is recommended that the gender affirmation process is performed by a team composed of a social assistance provider, mental health professionals (psychiatrist and psychologist), an endocrinologist, a gynecologist and a plastic surgeon, while the diagnosis and treatment are being determined. ${ }^{4,5}$

In addition, the centers that provide health assistance for this specific population must be connected to the SUS network, making the primary care centers the principal access to the health system. According to the offered protocol, in order to be submitted to a surgical procedure for sexual reassignment, an individual must be at least 21 years old, and have no less than 1 year of hormonal therapy and a 2-year follow-up with a mental health professional. It is important to distinguish, during the psychological evaluation, transgender dysphoria from other mental disorders that present with similar manifestations, as well as to identify and precisely treat psychiatric conditions that may be generated by the incongruence between gender identity and biological sex, such as anxiety, depression, auto-mutilation, compulsive behavior, drug abuse, personality and alimentary disorders and also autism spectrum disorders. ${ }^{5}$ Thus, it has been proposed that the diagnostic might be confirmed by a mental health professional who recommends hormonal therapy for those transgender individuals that desire to use it. ${ }^{5,6}$

\section{Recommendations for the Use of Testosterone in Male Transgenders}

The testosterone treatment's main goal is to start the development of male physical characteristics. The androgenization may be offered to transgender men who are 18 years old or older and who have characteristics of gender dysphoria/ gender incongruence, which must be attested by a mental health professional, and who also are completely capable of deciding to receive or not an individualized treatment, based on cost/benefit ratio, on social and economic issues and on individual specific necessities. ${ }^{5}$ The use of androgens for virilization is usually well tolerated and improves the quality of life and reduces the self-acceptance conflicts. However, there is still lack of evidence regarding the psychological effect of the long-term use of these hormones. ${ }^{7}$ The transgender men, before starting treatment, must be informed about the limitations and possible side effects that might advent from the androgen administration, such as irreversible physical alterations and the risk of infertility, although the severity and reversibility of this last side effect are not yet completely clarified. ${ }^{2}$ Some physical results may not be achieved, despite the dose of testosterone used; furthermore, the intentional use of supra physiologic doses of this hormone, greater than the male pattern, may lead to increased risk of complication. $^{7}$

The best moment to start the androgenic therapy is usually defined in collective agreement between the transgender individual that aims to start the transsexualization process and the mental health team that assisted him, diagnosed the gender dysphoria condition and recommended his sexual reassignment. ${ }^{5,6,8}$
Many different pharmacological formulations have been used by the health care services in the transsexualization process, including intramuscular testosterone esters in a short term or long-term release injection, undecanoate testosterone capsules, testosterone gel, patches or subcutaneous systems. Not every option is available for therapy in Brazil. $^{9}$ Oral testosterone (17 methyltestosterone or fluoximetazona) is not recommended because of excessive liver toxicity. The transdermal formulations, in gel or patch form, simulate the physiological release of testosterone, with minimal plasmatic oscillations. Usually, the side effects related to the transdermal use are secondary to skin-toskin contact in the gel form and cutaneous irritation in the patch form. Both presentations are high-cost drugs and the patch is not available in Brazil. The oral administration of undecanoate testosterone, 80 to $160 \mathrm{mg} /$ day, is not associated with hepatotoxic effect, and its intramuscular longterm release injection, 800 to $1,000 \mathrm{mg}$ every 12 weeks, keeps the plasmatic levels stable, with no peaks after administration. This drug is approved and available for therapy in Brazil, but its prohibitive cost makes it impracticable as a regular treatment, especially in the public health system. The most common used formulation is the intramuscular testosterone esters in a short-term release injection, the testosterone cypionate or enanthate, $200 \mathrm{mg}$ every 2 or 3 weeks. These are low-cost drugs and offer good tolerance and satisfactory clinical response, although they are not able to simulate the circadian rhythm and induce a supraphysiologic testosterone plasmatic level on the $1 \mathrm{st}$ days after administration (- Table 1). ${ }^{2,10}$

The androgenic therapy usually has a benefic psychological effect in transgender men, reducing anxiety, depression, emotional lability and humor disorders, probably due to the presence of androgen receptors all over the central nervous system. ${ }^{2}$ Although this improvement in psychological health may be due to a direct testosterone effect, it is more likely that this benefit on psychological symptoms are secondary to a reduction in the dysphoria caused by the physical alterations in response to the androgen therapy. ${ }^{9}$ Some transgender man still present with signs of anxiety and depression, even after the hormonal induced physical changes are complete, mainly those individuals who desire to have a surgical procedure for transsexualization.

In the majority of the testosterone therapy protocols, the male physical characteristics can be seen in almost all users after 6 months of therapy, and the maximum virilization effects are usually achieved after 3 to 5 years of regular use of the hormone. ${ }^{11}$ The increase in facial and corporal hair according to the male pattern can be observed after 4 to 6 weeks of treatment. Testosterone also progressively increases the hair follicle density, the thickness and the hair growth rate. ${ }^{5,9,11}$ However, as testosterone acts directly in the pilosebaceous unit, the hair growth rate is usually associated with acne and, in individuals with specific genetic predisposition, a long-term use can induce alopecia. ${ }^{9}$ Another collateral effect that may occur as a consequence of androgenic therapy is clitoromegaly $(3.5-5.0 \mathrm{~cm})$, which can be associated with pain in $20 \%$ of the cases, especially 
Table 1 Testosterone formulations

\begin{tabular}{|l|l|l|l|}
\hline $\begin{array}{l}\text { Composition } \\
\text { (testosterone) }\end{array}$ & Dose & Advantages & Disadvantages \\
\hline $\begin{array}{l}\text { Cypionate or Enanthate } \\
\text { Intramuscular route }\end{array}$ & $\begin{array}{l}200 \mathrm{mg} \text { every } \\
2-3 \text { weeks }\end{array}$ & Low cost & $\begin{array}{l}\text { Does not mimic testosterone } \\
\text { circadian rhythm } \\
\text { Plasmatic levels of testosterone } \\
\text { reach high non-physiological levels } \\
(800-1,000 \mathrm{ng} / \mathrm{dL} \text { ) in the first days } \\
\text { after administration }\end{array}$ \\
\hline $\begin{array}{l}\text { Undecanoate testosterone } \\
\text { oral route }\end{array}$ & $60-160 \mathrm{mg} /$ day & $\begin{array}{l}\text { Safe } \\
\text { (no hepatotoxicity) }\end{array}$ & 2-4 daily doses \\
\hline $\begin{array}{l}\text { Undecanoate testosterone } \\
\text { intramuscular route }\end{array}$ & $800-1,000 \mathrm{mg}$ every & $\begin{array}{l}\text { Stable concentrations } \\
\text { Physiologic doses }\end{array}$ & High cost \\
\hline Gel (1\%) (topic application) & $25-100 \mathrm{mg} /$ day & Stable concentrations & High cost \\
\cline { 3 - 4 } & & & Skin-to-skin contact transference \\
\cline { 3 - 4 } & & Stable concentrations & High cost \\
\cline { 2 - 4 } & & & Skin irritation \\
\cline { 3 - 4 } & & & Not available in Brazil \\
\hline Patch (topic application) & $2.5-10 \mathrm{mg} /$ day & & \\
& & &
\end{tabular}

in those transgender men treated with undecanoate testosterone. $^{9}$

Testosterone treatment seems to be associated with an increase in sexual desire of transgender men. A prospective study evaluating transgender men, with no history of psychiatric diseases or use of medication, who were submitted to different types of testosterone formulations in one year, demonstrated an increase in sexual desire, sexual fantasies and masturbation frequency in $70 \%$ of the individuals. However, no increase in the frequency of intercourse or in sexual satisfaction was reported. ${ }^{12}$

Voice alterations, similar to those observed in male puberty, have also been observed in male transgender after 3 to 6 months of treatment. Commonly, the voice gets deeper, although almost one third of male transgenders will need speech therapist support because of voice fatigue, instability, quality and projection. ${ }^{9}$

Testosterone therapy also modifies the body composition toward a male pattern, in general with higher muscular mass and lower adipose mass than females. A period of up to 2 years of androgen administration is needed to produce a redistribution of body fat with more pronounced truncal adiposity. An increase in 1.5 to $6.0 \mathrm{Kg}$ of lean mass may also occur, with a correspondent increase in muscular strength and a reduction in 2 to $4 \mathrm{Kg}$ in body fat. ${ }^{13}$

Typically, testosterone can induce alteration in the vaginal epithelium, clinically manifested by signs of mucosa atrophy. Transgender men treated with intramuscular testosterone presented a thinner vaginal epithelium, with loss of superficial and intermediate layers and intracytoplasmic glycogen reduction, similar to that observed in postmenopausal women. $^{5}$

One of the main goals of transgender men under androgen therapy is the achievement of amenorrhea, which contributes enormously to the psychological well-being in these individuals. With the usual recommended therapeutic doses, amenorrhea will occur in $90 \%$ of the patients in the first 6 months, reaching almost $100 \%$ after 1 year of treatment. ${ }^{8}$ Although menstrual cycles are suspended, the endometrial evaluation in male transgenders has shown inconsistent results. In one study, all the evaluated samples indicated inactive endometrium, similar to the endometrium seen in postmenopausal women but in another study, only half of the patients presented atrophic endometrium, while in the other half a proliferative endometrium was found even after 2 to 9 months of androgenic therapy. ${ }^{9}$

Even though the role of androgenic therapy on the ovaries has been widely discussed, no definitive conclusions were made. Testosterone may lead to stromal hyperplasia and increase ovarian volume, which assumes a polycystic morphology, defined by the presence of 12 or more preantral follicles per ovary, in mostly all transgender men. However, more recent data have shown that the ovarian morphology in these individuals, analyzed by tridimensional ultrasound, does not differ from the ovaries of cycling women, suggesting that androgen therapy in transgender man does not necessarily induce a polycystic ovary morphologic pattern. ${ }^{14}$

Mammary tissue is another target that seems to have its composition altered by testosterone therapy. ${ }^{9}$ Histological analyses of mammary tissues from androgen treated transgender men submitted to mastectomy during the transsexualization process have evidenced a substantial reduction in glandular and adipose tissues and an increment in the fibrous connective tissue. No atypical hyperplasia or carcinoma were reported during a follow-up of 19 years under androgen therapy. ${ }^{15}$ The estimated risk of breast cancer in transgender men under testosterone therapy is $5.9(0.5-27.4)$ cases per 100,000 persons/year, while this risk for normal women is 155 cases per 100,000 women/year. ${ }^{15}$ More studies are necessary to confirm these data. 
Other comorbidities, such as sleep apnea, impairment in lipid profile, insulin sensitivity reduction, polycythemia, venous thromboembolism, arterial hypertension and atherosclerosis, can be worsen or be initiated by the chronic use of androgen therapy, potentially increasing cardiovascular risk. ${ }^{16}$ However, the use of different testosterone formulations does not seem to affect the systemic arterial blood pressure, the carotid intima media layer thickness nor the deposition of calcium in the coronary arteries. Also, no effect on fasting glucose, intensity of insulin resistance, or venous thromboembolism risk has been reported. ${ }^{9,16}$ A recent metaanalysis concluded that the cardiovascular risk evaluation in transgender men submitted to androgen therapy is limited due to several weaknesses: low level of evidence obtained from a few observational studies, lack of control group, small subjects number, comparison of different androgen therapy protocols, short-term follow-up and beginning of therapy before 30 years of age, when the cardiovascular risk itself is naturally very low. ${ }^{17}$

It is recommended that transgender men under androgen therapy should be monitored for cardiovascular risk every 3 months during the 1 st year after treatment initiation and then every 6 to 12 months. The protocols suggested by the Endocrine Society Clinical Practic ${ }^{8}$ and the WPATH ${ }^{4}$ recommend that, to minimize risks, plasmatic testosterone levels should be kept within male physiological ranges (300-1,000 ng/dl) during hormonal treatment. Gonadotrophin levels can be suppressed, but in some cases, they can be above normal follicular phase ranges, suggesting that the hypothalamus-hypophysis-ovary (HHO) axis may not be suppressed by male physiologic levels of androgen. ${ }^{1}$ This reinforces the importance of contraceptive measures for transgender men that practice penis-in-vagina intercourse with men or transgender women. Estradiol measurement during the first 6 months of therapy may help monitoring the activity of the HHO, once suppressed levels of estradiol $(<50 \mathrm{pg} / \mathrm{ml})$ associated to amenorrhea suggests a blocked axis. ${ }^{16}$ Concentrations of estradiol $<30 \mathrm{pg} / \mathrm{ml}$ combined with $\mathrm{FSH}>40 \mathrm{UI} / 1$ might be better markers of ovarian suppression.

It is recommended that testosterone levels be measured 7 to 10 days after intramuscular testosterone esters injection, nearby the nadir levels or at any time after 1 week of transdermal androgen use. Estradiol levels shall be evaluated after 6 months of treatment or after amenorrhea is installed. From the metabolic point of view, blood pressure, lipid profile, fasting glucose and hematocrit shall be monitored before and every 3 months on the 1 st year of androgen therapy. ${ }^{8}$ Because testosterone can be aromatized in estradiol, its long-term effects on ovary, uterus and breast are not completely defined, thus screening for endometrial, ovarian, and breast cancer shall be performed in agreement with the particularities of each case. A pelvic ultrasound may be performed every 6 months or whenever the health assistance provider believes it is necessary. ${ }^{1,8,12}$

According to the literature, it seems that androgen therapy for transgender men may be prescribed for the whole life. There is not enough evidence to determine if this is the best treatment for all transgender individuals or only for those submitted to oophorectomy.

A higher overall mortality has been described in transgender individuals, but available data cannot establish a cause and effect correlation between long-term use of testosterone as the main cause of death in this population; instead, it suggests that drug abuse, sexually transmitted diseases (STDs), mainly HIV-AIDS, and suicide are more frequent. Thus, in addition to HIV, hepatitis, and other STD screening, it is recommended that mental disorders screening should also be included in the routine follow up of transgender men, because of its high prevalence in this population who live under the chronic stress that is still imposed on some minorities. 5,6

\section{Conclusion}

1. Gender affirmation is multidisciplinary treatment.

2. The androgenization may be offered to transgender men, 18 years old or over, who have proven gender dysphoria attested by a mental health professional.

3. Transgender men require an effective hormone regimen by means of testosterone administration that start the development of male physical characteristics and maintain sex hormone levels within the normal range for the person's affirmed gender.

4. The use of testosterone is usually well tolerated and improves the quality of life.

5. There still a lack of evidence regarding the effects of the long-term use of these hormones

6. In the Brazilian Public Health System, the transsexualization process was institutionalized by means of the health ministerial order, which allowed for a larger number of health centers to be able to offer treatment to this population.

\section{Conflicts of Interest}

This revision was elaborated by the Specialized National Committees on Endocrine Gynecology at Federação Brasileira das Associações de Ginecologia e Obstetrícia.

\section{References}

1 Trum HW, Hoebeke P, Gooren LJ. Sex reassignment of transsexual people from a gynecologist's and urologist's perspective. Acta Obstet Gynecol Scand 2015;94(06):563-567. Doi: 10.1111/ aogs. 12618

2 Meriggiola MC, Berra M. Safety of hormonal treatment in transgenders. Curr Opin Endocrinol Diabetes Obes 2013;20(06): 565-569. Doi: 10.1097/01.med.0000436187.95351.a9

3 American Psychiatric Association. Diagnostic and Statistical Manual of Mental Disorders: DSM-5. $5^{\text {th }}$ ed. Washington, DC: American Psychiatric Association; 2013

4 Ministério da Saúde. Portaria No. 2.803, de 19 de novembro de 2013. http://bvsms.saude.gov.br/bvs/saudelegis/gm/2013/ prt2803_19_11_2013.html. Accessed August 14, 2017

5 The World Professional Association for Transgender Health. Standards of Care for the Health of Transsexual, Transgender, and Gender Nonconforming People, $7^{\text {th }}$ version. 2012. https://www.wpath.org/media/ 
cms/Documents/Web\%20Transfer/SOC/Standards\%20of\%20Care\% 20V7\%20-\%202011\%20WPATH.pdf. Accessed September 10, 2017

6 Wylie K, Knudson G, Khan SI, Bonierbale M, Watanyusakul S, Baral S. Serving transgender people: clinical care considerations and service delivery models in transgender health. Lancet 2016;388 (10042):401-411. Doi: 10.1016/S0140-6736(16)00682-6

7 Costa EMF, Mendonça BB. Clinical management of transsexual subjects. Arq Bras Endocrinol Metabol 2014;58(02):188-196. Doi: 10.1590/0004-2730000003091

8 Hembree WC, Cohen-Kettenis PT, Gooren L, et al. Endocrine treatment of gender-dysphoric/gender-incongruent persons: an Endocrine Society Clinical Practice guideline. J Clin Endocrinol Metab 2017;102(11):3869-3903. Doi: 10.1210/jc.2017-01658

9 Irwig MS. Testosterone therapy for transgender men. Lancet Diabetes Endocrinol 2017;5(04):301-311. Doi: 10.1016/S22138587(16)00036-X

10 Gardner IH, Safer JD. Progress on the road to better medical care for transgender patients. Curr Opin Endocrinol Diabetes Obes 2013; 20(06):553-558. Doi: 10.1097/01.med.0000436188.95351.4d

11 Bishop BM. Pharmacotherapy considerations in the management of transgender patients: a brief review. Pharmacotherapy 2015; 35(12):1130-1139. Doi: 10.1002/phar.1668

12 Costantino A, Cerpolini S, Alvisi S, Morselli PG, Venturoli S, Meriggiola MC. A prospective study on sexual function and mood in female-to-male transsexuals during testosterone administration and after sex reassignment surgery. J Sex Marital Ther 2013;39(04):321-335. Doi: 10.1080/0092623X.2012.736920

13 Van Caenegem E, Wierckx K, Taes Y, et al. Body composition, bone turnover, and bone mass in trans men during testosterone treatment: 1-year follow-up data from a prospective case-controlled study (ENIGI). Eur J Endocrinol 2015;172(02):163-171. Doi: 10.1530/EJE-14-0586

14 Caanen MR, Schouten NE, Kuijper EAM, et al. Effects of long-term exogenous testosterone administration on ovarian morphology, determined by transvaginal (3D) ultrasound in female-to-male transsexuals. Hum Reprod 2017;32(07):1457-1464. Doi: 10.1093/ humrep/dex098

15 Gooren LJ, van Trotsenburg MA, Giltay EJ, van Diest PJ. Breast cancer development in transsexual subjects receiving cross-sex hormone treatment. J Sex Med 2013;10(12):3129-3134. Doi: $10.1111 /$ jsm. 12319

16 Bourgeois AL, Auriche P, Palmaro A, Montastruc JL, Bagheri H. Risk of hormonotherapy in transgender people: Literature review and data from the French Database of Pharmacovigilance. Ann Endocrinol (Paris) 2016;77(01):14-21. Doi: 10.1016/j.ando.2015.12.001

17 Elamin MB, Garcia MZ, Murad MH, Erwin PJ, Montori VM. Effect of sex steroid use on cardiovascular risk in transsexual individuals: a systematic review and meta-analyses. Clin Endocrinol (Oxf) 2010;72(01):1-10. Doi: 10.1111/j.1365-2265.2009.03632.x 